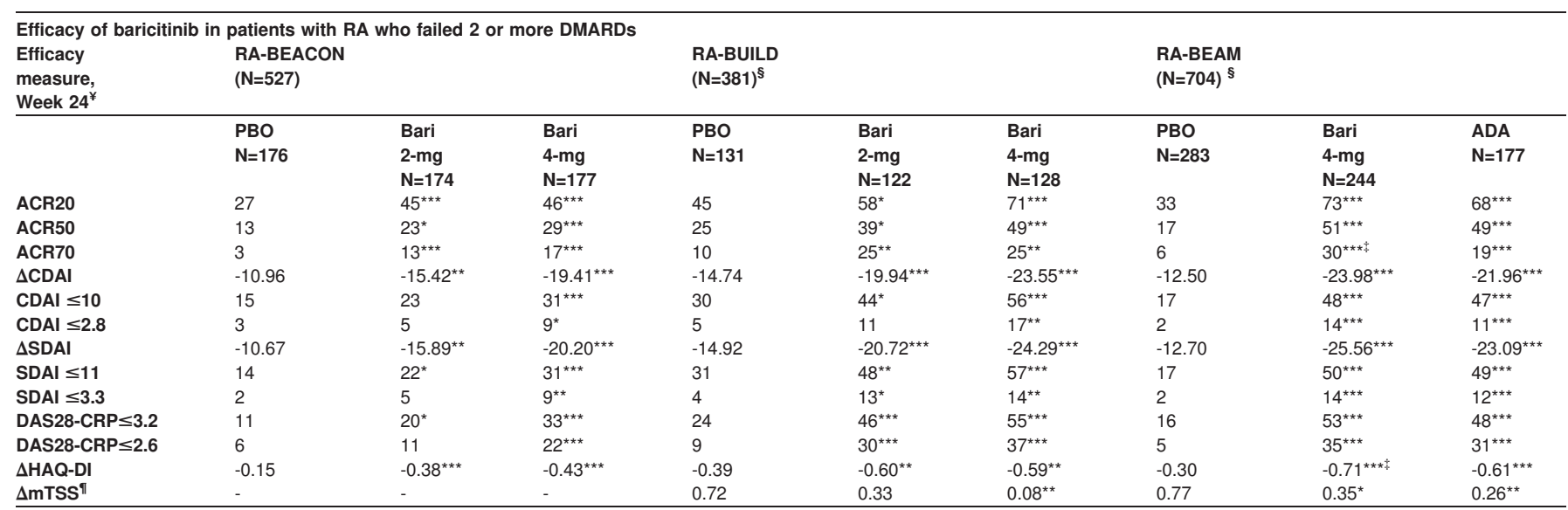

[2] Braun J, et al. A\&R 2008;58(1):73-81.

[3] Hazlewood GS,eta I. T. Ann Rheum Dis 2016;75(6):1003-08.

Disclosure of Interest: None declared

DOI: 10.1136/annrheumdis-2018-eular.7556

\section{SAT0236 LONG-TERM SAFETY AND EFFICACY OF UPADACITINIB (ABT-494), AN ORAL JAK-1 INHIBITOR IN PATIENTS WITH RHEUMATOID ARTHRITIS IN AN OPEN LABEL EXTENSION STUDY}

M. C. Genovese ${ }^{1}$, J. Kremer ${ }^{2}$, S. Zhong ${ }^{3}$, A. Friedman ${ }^{3} .{ }^{1}$ Stanford Univ, Palo Alto, ${ }^{2}$ Albany Medical College, Albany, ${ }^{3}$ AbbVie Inc., North Chicago, United States

Background: Upadacitinib (UPA, ABT-494) is a selective, oral JAK-1 inhibitor studied in two phase 2 randomized controlled trials (RCTs) in patients (pts) with rheumatoid arthritis (RA).

Objectives: We assessed UPA safety and efficacy in BALANCE-EXTEND, an ongoing, combined open-label extension (OLE) of the phase 2 RCTs.

Methods: Pts completing the two 12-week RCTs (in TNF-IR and (MTX-IR pts) ${ }^{1,2}$ could enter the OLE. Pts switched to 6 mg UPA from their RCT dose of UPA 3, 6 , $12,18 \mathrm{mg}$ twice daily (BID), $24 \mathrm{mg}$ once daily (QD) or Placebo. A dose increase to $12 \mathrm{mg}$ BID was required for pts with $<20 \%$ improvement in both SJC and TJC on 6 mg BID (at wk 6 or 12), and permitted for pts not meeting CDAI LDA. Pts without $20 \%$ improvement in SJC and TJC 6 wks after escalation, or at any 2 consecutive visits, were discontinued. The dose was decreased to $6 \mathrm{mg} \mathrm{BID}$ only in pts with a safety concern or intolerability. Pts are grouped as: Never-titrated (on $6 \mathrm{mg}$ BID throughout); Titrated-up (from 6 to $12 \mathrm{mg} \mathrm{BID}$ ); Titrated-up and back down (to 6

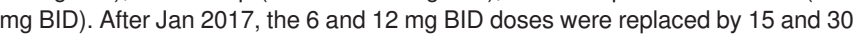
$\mathrm{mg}$ QD extended-release equivalents currently being studied in phase 3 . Data up to Jan 132017 are reported. Adverse events (AE) per $100 \mathrm{yrs}$ of pt exposure (PY) are summarized starting from day 1 of OLE. Efficacy is assessed by ACR20/50/70 and LDA (by DAS28-CRP and CDAI), and observed data are presented up to Wk 72 of OLE due to sample size consideration.

Results: Out of 516 pts who completed the 2 RCTs, 494 entered the OLE, 493 were dosed, $328(66.5 \%)$ were never-titrated, $150(30.4 \%)$ were titrated-up, and $15(3 \%)$ were titrated-up and back down; 150 pts $(30.4 \%)$ were discontinued [42 (8.5\%) withdrew consent, $37(7.5 \%)$ due to $\mathrm{AE}$ and $24(4.9 \%)$ due to lack of efficacy]. Mean exposure to UPA was $525.4 \pm 221.4$ days (range 1-961 days), and cumulative exposure was 725.1 PY (Table). The E/100PY for any AE in the OLE (170.5) were lower than for the RCTs in the TNF-IR (697.9, 48 PY) and MTX-IR (408.4, 54.6 PY) study populations. The E/100PY were 2.3 for serious infection, 3.7 for herpes zoster, 0.8 for malignancies excluding non-melanoma skin cancer, and 0.7 for adjudicated cardiovascular events. There were 2 deaths: one sudden death (adjudicated as undetermined or unknown cause of death) and one death due to Hodgkin's lymphoma. Changes from baseline in laboratory parameters were consistent with observations from phase 2 RCTs. For those pts completing Wk 72, efficacy was maintained in pts on $6 \mathrm{mg}$ BID UPA from day 1 of OLE (never-titrated); $55 \%$ pts met ACR70 and $83 \%$ were in LDA by DAS28-CRP and CDAl based on as observed data (Table).

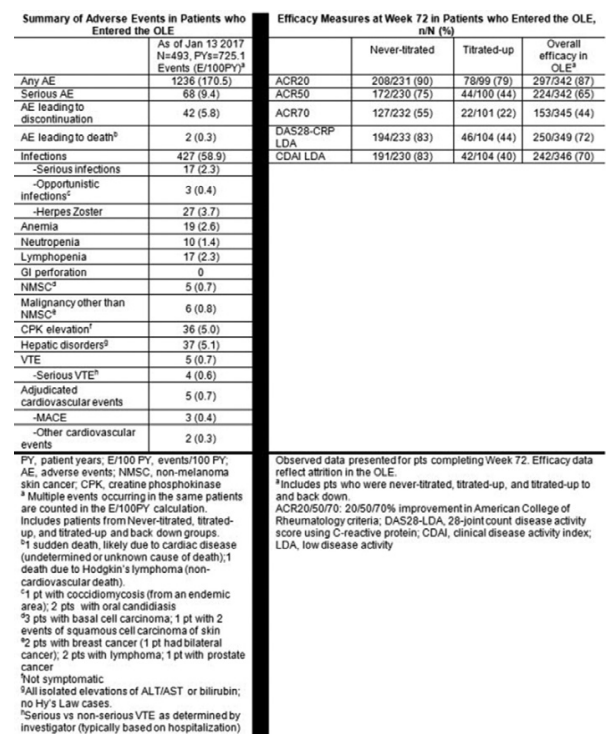

Conclusions: The safety profile of UPA remained consistent with that expected for an RA population treated with JAKi. Efficacy responses were maintained up to 72 wks in pts on $6 \mathrm{mg} \mathrm{BID} \mathrm{UPA}$ in the OLE.

\section{REFERENCES:}

[1] Kremer, et al. Arth \& Rheum 2016;68:2867

[2] Genovese, et al. Arth \& Rheum 2016;68:2857.

Acknowledgements: AbbVie and the authors thank the patients, study sites and investigators who participated in this clinical trial. AbbVie Inc was the study sponsor, contributed to study design, data collection, analysis \& interpretation, and to writing, reviewing, and approval of final version. Medical writing support was provided by Naina Barretto, $\mathrm{PhD}$, of AbbVie, Inc.

Disclosure of Interest: M. Genovese Grant/research support from: AbbVie, Lilly, Astellas, Pfizer, Galapagos, Gilead, Consultant for: AbbVie, Lilly, Astellas, Pfizer, Galapagos, Gilead, J. Kremer Shareholder of: Corona, Grant/research support from: AbbVie, Lilly, Novartis, Pfizer, Medlmmune, Sanofi, and Regeneron, Consultant for: AbbVie, Lilly, Novartis, Pfizer, Medlmmune, Sanofi, and Regeneron, Employee of: Corona, S. Zhong Shareholder of: AbbVie, Employee of: AbbVie, A. Friedman Shareholder of: AbbVie, Employee of: AbbVie DOI: 10.1136/annrheumdis-2018-eular.7021 